\title{
Allocation improvement policies to reduce process time based on workload evaluation in job shop manufacturing systems
}

\section{Paolo Renna*}

School of Engineering, University of Basilicata, Via dell'Ateneo Lucano, 10, 85100 - Potenza, Italy

\begin{tabular}{l}
\hline C H R O N I C L E \\
\hline Article history: \\
Received October 202016 \\
Received in Revised Format \\
October 28 2016 \\
Accepted December 22016 \\
Available online \\
December 2 2016 \\
\hline Keywords: \\
Controllable process time \\
Job-shop \\
Allocation improvements \\
Workload control \\
Simulation
\end{tabular}
A B S T R A C T

\begin{abstract}
The research discusses in this paper concerns the improvement allocation policies to reduce the process time in job-shop manufacturing systems. The policies proposed are based on the evaluation of the workload control of the entire manufacturing system. Three policies are proposed: centralized, distributed and proportional. A simulation model is used to test the proposed policies under different conditions as: static and dynamic demand; introduction of machine breakdowns; different level of average manufacturing system utilization. The performance measures are compared to a manufacturing system without policies. The simulation results show that the improvement allocation allows to improve the performance with limited investment (average reduction of process time needed) and how the machine breakdowns and demand changes lead to different better policy. The decision maker can use these results to decide the better policy to use.
\end{abstract}

\section{Introduction}

The companies to stay competitive should have continuous improvement programs, which involves the entire organizations (Goldratt \& Fox 1986; Pande et al., 2000; Bhuiyan \& Baghel, 2005). At the shop floor level, the production managers have to increase the throughput rate, reduce the costs, improve the customer satisfaction in terms of quality, delivery time, etc. In this context, the decision where to focus the limited investment for the improvement areas of the manufacturing system is crucial to improve the performance of production systems. Some examples to focus the improvements can be the reduction of: variability of the process time, mean set-up time, mean time between failures, mean time to repair and demand variability. Janiak (1989) described the scheduling problem with controllable processing times in steel mills where the preheating time and the rolling time are inversely proportional to the gas flow intensity. Other examples of the combining deteriorating effect and controllable processing times are reported in Janiak et al. (2011) and Renna (2015a).

\footnotetext{
* Corresponding author Tel.: +390971 205143

E-mail: paolo.renna@unibas.it (P. Renna)

(C) 2017 Growing Science Ltd. All rights reserved. doi: $10.5267 / j . i j i e c .2016 .12 .001$
} 
The main strategies proposed in the literature are: centralized approach that focuses the improvements on the Capacity Constraint Resource (CCR, Goldratt and Cox, 1984); the distributed approach that shares the improvements on the resources (Womack et al., 1990); the hybrid strategy that combines the centralized and distributed approaches (Godinho Filho \& Utiyama, 2015). These strategies are proposed and tested only for the case of production lines.

The research proposed concerns the allocation of improvements programs to reduce the process time in order to obtain the better balance between performance and costs. The allocation of the improvements is based on the evaluation of the workload of the shop-floor. Workload control is a production planning control particular relevant for Make-To-Order (Stevenson et al., 2005; Fernandes \& Carmo-Silva, 2011).

Three policies are proposed: centralized, distributed and proportional. A simulation environment is developed to evaluate the proposed approach in static and dynamic demand conditions. The results of the simulations can support the decision maker to focus the investment and to improve the performance of the production system when the conditions change.

The paper is organized as follows. Section 2 presents an overview of the literature; the reference context is described in Section 3. The allocation improvements policies are described in Section 4. The simulation environment is presented in Section 5, while Section 6 provides a discussion of the simulation results. Finally, conclusions and future research paths are drawn in Section 7.

\section{Overview of the literature}

The studies proposed in literature concern mainly three issues: controllable processing time, improvements allocation programs and workload control. Few research integrates the above areas to support the decisions in production systems to reduce the process time based on improvement investments.

The controllable process time approach can be a valid policy to improve the performance both in job shop and mixed model assembly line (Battini et al., 2010). The main works on controllable process times in literature are associated with mathematical models applicable in limited industrial cases. A complete survey presented by Shabtay and Steiner (2007) underlined many open questions in the area of multimachine problems with controllable processing times. Selim and Taylan (2011) studied the control of the processing time considering the control of cutting force in a milling CNC machine. Examples taken from experimental tests have shown that the developed approach is effective for the uncertain CNC machine. Some recent papers studied the problem of controllable processing time for flow-shop scheduling problem (Mokhtari et al., 2011; Uruk et al., 2013). A real industrial application is implemented for Gienow Windows and Doors Ltd. Based on the optimal resource allocation for hybrid flow shop in oneof-a-kind production to achieve an optimal resource allocation plan ensuring that all jobs are finished in a given time interval (Luo et al., 2010).

Some approaches have been proposed in case of job-shop scheduling problem; It is proposed searchbased metaheuristic, which can be used with a limited number of machines due to the computational complexity (Yildiz et al., 2011; Niu et al. 2012). Renna (2013b) presented two approaches for processing time control in flexible manufacturing systems supported by a multi agent architecture. The method considered limited amount of resources to allocate among the manufacturing resources evaluating the workload. The first approach focused only to the resource with higher workload, while the second approach distributes the resources proportionally among the machines. The simulation results show how the control processing time policies proposed allow to improve significantly the performance measures of the manufacturing system. The main limit of the proposed approaches is the definition of a set of parameters in advance. The above approaches can support reconfigurable manufacturing systems for the reconfigurations of the job shop (Renna, 2013a.). Moon et al. (2014) proposed an evolutionary method 
with a simulation model for scheduling operations with specified workload and with processing times dependent on resource assignment.

Among the recent papers on improvement allocation problems in production systems, Renna (2010) proposed a policy to improve the due date performance by the capacity improvement program among different production lines. The policy concerns the estimation of delay or early of parts due date in queue and the shifting of capacity among the manufacturing lines is based on this estimation. Godinho Filho and Uzsoy (2011) and Godinho Filho (2012) studied the effects of several continuous improvement programs in production lines with one kind of product using the system dynamics approach. Their results show that the relationship between lot sizes, cycle times, and shop floor parameters is complex and nonlinear. The research shows the benefit of the continuous improvement programs for the different conditions for the main performance measures. Godinho Filho and Uzsoy (2015 and 2014) conducted simulation experiments to compare for the allocation of improvement programs in a flow shop environment with a single product type. They studied the cumulative effect of continuous improvement in arrival variability, process variability, defect rate, time to failure, repair time and setup time on operating curves in a flow shop environment. Their results show the improvements of the performance for different level of utilizations. Guimaraes et al. (2013) studied the effect of six shop floor improvement programs on lead time for several production system characteristics. The improvement programs studied were the following: improvement in setup time, defect rate, repair time, time between failures, processing time variability and arrival variability. All the improvement programs presented statistically significant contributions for lead time reduction in at least some production environments studied, except improvement in the arrival coefficient. The great part of the research on WorkLoad Control (WLC) concerns the continuous order release (Fernandes \& Silva, 2011), the effect of protective capacity (Fernandes \& Silva, 2014; Thürer et al., 2012, 2015). Then, the workload control is studied only for the order release decision in manufacturing systems (Renna, 2015b). Thürer et al. (2016) integrated the Workload Control (input control) and capacity adjustment (output control) in a job shop context. The capacity adjustment concerns the reduction of the processing time.

Based on the above literature review, the following limits can be drawn:

a) The large part of the approaches proposed in literature is characterized by high computational complexity and related to simplify manufacturing systems. This reduces the possibility to introduce these approaches in real industrial cases.

b) The great part of the research on allocation of improvement programs did not study the reduction of process time; several works are based on system dynamic models with reduced detail of the simulation model compared to a discrete event simulation model more appropriate for discrete production systems.

c) The integration of workload control, controllable processing time and allocation of improvement programs was studied in literature in one research (Thurer et al., 2016).

The research proposed in this paper resulted to the above limitations in the following issues:

a) The proposed methodology integrates the workload control, improvement allocation of limited resources available and controllable process time to keep high level of performance when the operational conditions change. Thurer et al. (2016) does not consider limited resources to share among the work centers to reduce the processing time.

b) Three policies are proposed to share the improvement resources, while Thurer et al. (2016) considered only a workload threshold to reduce the processing time of the work centers.

c) This research proposes a discrete event simulation model with higher details than the model proposed in literature. The analysis considers a wider range of performance measures than the works proposed.

The analysis conducted can support managers to define the suitable policy based on the main important performance measure from the firms' point of view. 


\section{Reference context}

In order to evaluate the proposed approaches, we have considered a model introduced in previous studies (Oosterman et al., 2000; Melnyk and Ragatz, 1989) and applied in many studies afterwards. The jobshop consists of six work centers, and each work center is characterized by one machine. When a job enters into the production system, it is assigned a random routing sequence, the processing time in each machine and the due date. As in previous simulation studies on Workload Control (Land and Gaalman, 1996; Thurer et al., 2012; Fredendall et al., 2010), it is assumed that all jobs are accepted, materials are available and all necessary information. The main assumptions of the model tested are the following: Operations cannot be pre-empted; each machine can process only one task at once; the queues are managed by the First In First Out (FIFO) policy (this to evaluate only the performance of the proposed methodology); each machine can breakdown randomly.

In this research, the material handling time is included in the machining time, and the handling resources are always available. When a part enters in the shop floor, the workload of the work centers (that is involved in the manufacturing of the part) is updated according the routing of the part. When a part leaves a work center, the workload of this work center is reduced.

The total investment available for the improvement programs allows to reduce the process time of $60 \%$, if the investment focuses on a single work center (centralized approach, see Fig. 1). Otherwise, if the investment is distributed among the six work centers the reduction can be $10 \%$ for each work center (distributed approach, see Fig. 2). The proportional approach (see Fig. 3) distributed the $60 \%$ of the process time reduction proportionally to an index of the machine described in the following Section that depends on the machine utilization.

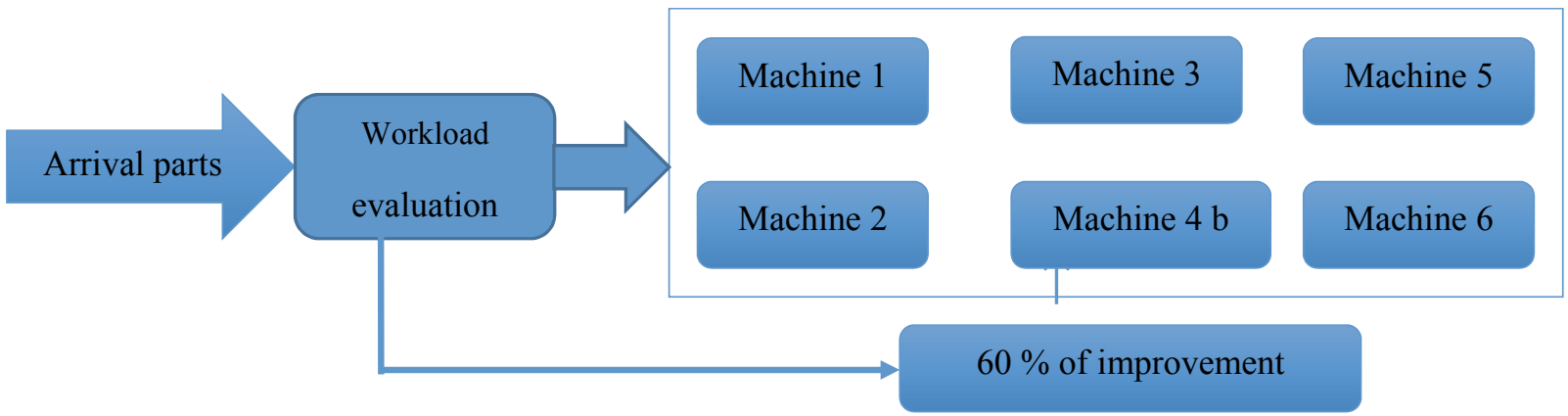

Fig. 1. Centralized approach

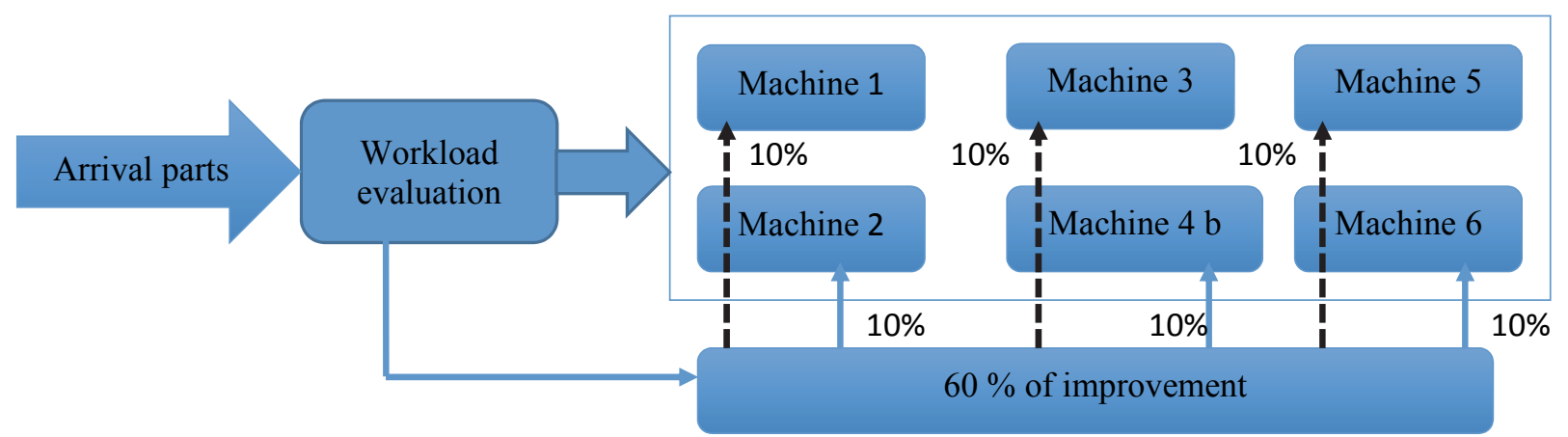

Fig. 2. Distributed approach 


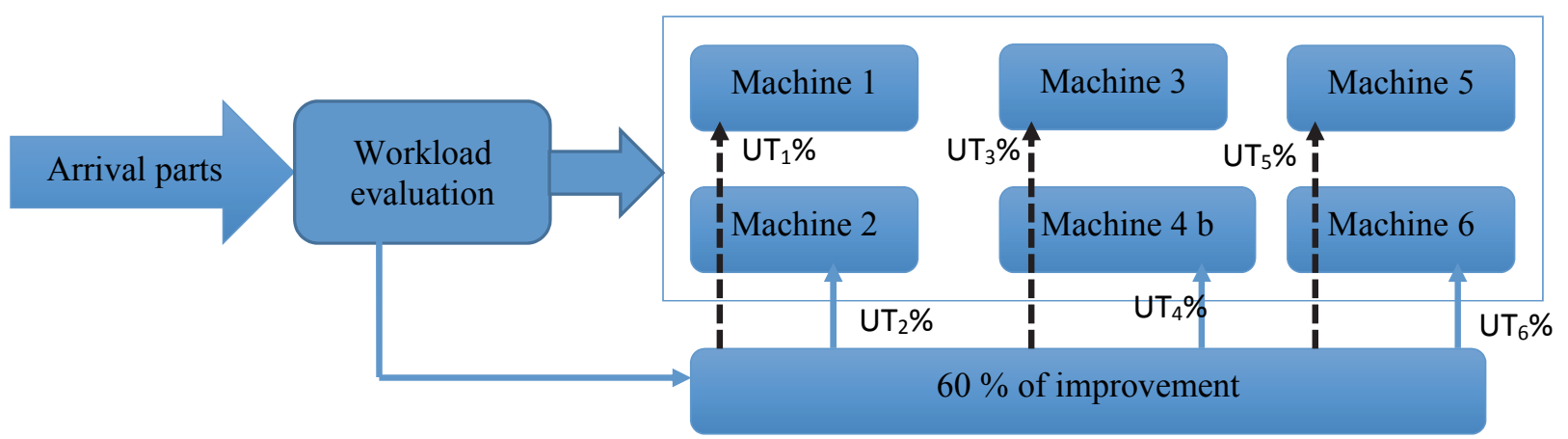

Fig. 3. Proportional approach

The notation used in next sections is the following.

\section{Notation:}

$m=1, \ldots M$ is the work center that is composed by one machine; therefore, the term work center and machine will be used indifferently. Each machine performs a particular technological operation.

$i$ is the part index of the parts

$t$ is the time of the decision

$T p$ is the periodic review time

Topim is the process time of the technological operation performed by the machine $m$ of the part $i$

$a_{i m}$ is a binary value that defines if an operation assigned to machine $m$ needs to be performed by the part $i$

$U t_{m}(t)$ is the average utilization of the machine $m$ at time $t$

$A V U t_{m}(t)$ is the moving average utilization of the machine $m$ at time $t$, over the last Tp observed

$D D_{i}$ is the due date of the part $i$

$W L_{m}$ workload of the machine $m$

When a part enters the manufacturing system, the workload of the machines is updated as follows:

$$
W L_{m}=\sum_{m=1}^{M} \operatorname{Top}_{i m} * a_{i m} \vee m
$$

When a part leaves the generic $m$ machine, the workload is reduced as follows:

$$
W L_{m}=W L_{m}-T o p_{i m}
$$

\section{Allocation improvement policies}

The production system can use limited resources to improve the manufacturing operations in the work centers reducing the process time, but increasing the processing costs due to the improvement investments. The allocation policy supports the following decisions: when the resources available will be allocated and the work centers to support reducing the process time. In this research, three policies are proposed and described in the following: centralized, distributed and proportional.

\section{Centralized policy}

The centralized policy allocates all the resources available to one work center reducing the process time of $60 \%$. For each work center is known the workload $W L_{m}(t)$ computed as shown in eq. (1 and 2); the first work center that has a workload greater than a higher threshold (HT, eq. 3) acquire the entire resource available.

$$
W L_{m}(t)>H T
$$


The resources available of the manufacturing system are set to 0 ; therefore, if another work center $m$ have a WL greater than the HT, the work center cannot reduce the process time.

When the workload is lower than a Lower Threshold ( $L T, e q .4)$, the work center releases the resources available to the production system.

$$
W L_{m}<L T
$$

The strategy of uses an interval [HT-LT] is necessary to reduce the number of improvement operations and obtain a suitable stability for the process time reduction.

\section{Distributed policy}

In this case, each work center has an amount of resources dedicated and available for the $10 \%$ of process time reduction. When a generic work center has a workload greater than the HT (eq. 3), the resources are allocated to the work center and the resource is released when the work center verifies eq. 4 . This policy allows to reduce the process time to all work centers with higher workload, but with lower reduction of the processing time. Moreover, the investment is dedicated to reduce the $10 \%$ for each work center. For example, each work center has some tools able to reduce the process time, but with higher costs. Therefore, this policy supports the choice among tools with different performance and costs.

\section{Proportional policy}

This policy distributes the resources to the work centers proportionally to the average utilization of the work centers. A weighted moving average is computed on the utilization of each work center $A V U t_{m}(t)$. Then, it is computed a normalized index to distribute the available resources to the work centers as shown in Eq. (5).

$$
\begin{aligned}
& \text { index }_{m}(t)=\frac{A V U t_{m}(t) * X_{m}}{\sum_{m=1}^{M} A V U t_{m}(t) * X_{m}} \\
& X_{m}=\left\{\begin{array}{c}
1, \text { if } W L_{m}(t)>H T \\
0, \text { otherwise }
\end{array}\right.
\end{aligned}
$$

The resource available are distributed proportionally to the index $(t)$, only to the work centers that have workload higher than the $H T$. The computation and allocation of the above distribution work on a periodic review time (in this research, 1000 unit time $\left(T_{p}\right)$ ).

\section{Simulation model}

The simulation environment developed is based on the multi-domain software ExtendSim ${ }^{\circledR}$ by Imagine That Inc. ExtendSim is a simulation program for modeling discrete event, continuous, agent-based, and discrete rate processes. The simulation model consists of 4 modules:

- Module designed to generate a uniform casual routing of the parts on the six work centers of the manufacturing system;

- Module designed for the assign the parts to the work centers according the routing generated and compute the workload of the work centers due to the parts;

- The manufacturing system module for the six work centers and the reduction of the workload when a part performs a manufacturing operation;

- A module that performs the policy to allocate the resources to the work center and reduces the process time. 
Table 1 reports the simulation data; in particular, when an order enters it is assigned a number of operations following a uniform distribution and at each operation extracted is assigned a uniform work center. This allows to obtain results independent from the particular routing assigned to the orders. At each operation to perform in a work center is assigned a process time following a uniform distribution. The simulations are conducted for three inter-arrival parameters (exponential distribution) to evaluate the proposed methodology with different values of manufacturing system utilization. The three approaches are tested with a fixed level of the Lower Threshold (LT) and six values of Higher Threshold (HT). The demand changes are tested between maximum and minimum value of inter-arrival parameter with three period time of change to test the effect of demand fluctuations.

Table 1

Simulation data

\begin{tabular}{|c|c|c|c|}
\hline Routing of the parts & & & \\
\hline Number of operations & UNIF[1,6] & Work center $m$ & UNIF[0,1] \\
\hline Process time & UNIF $[1,3]$ & & \\
\hline Resources available & \multicolumn{3}{|c|}{ Total $60 \%$ of process time reduction } \\
\hline & High & Medium & Low \\
\hline Inter-arrival & $\operatorname{EXPO}(1.1)$ & $\operatorname{EXPO}(1.2)$ & $\operatorname{EXPO}(1.3)$ \\
\hline Threshold levels & $\mathrm{LT}=3$ & \multicolumn{2}{|c|}{$\mathrm{HT}=6-9-12-15-18-21$} \\
\hline & MTBF & \multicolumn{2}{|l|}{ MTTR } \\
\hline \multirow[t]{2}{*}{ Failure data } & $\mathrm{N}(300,30)$ & \multicolumn{2}{|l|}{$\mathrm{N}(30,3)$} \\
\hline & Time change 1 & Time change 2 & Time change 3 \\
\hline Demand fluctuations EXPO(1.3-1.1) & 500 & 350 & 650 \\
\hline
\end{tabular}

The simulation length is fixed to 10,000 unit time and the due date is computed as follows:

$$
D D_{i}=\text { Tnow }+U N I F[1.2,2] * \sum_{m=1}^{M} a_{i m} * T_{o p} p_{i m}
$$

The number of experimental classes includes: 3 approaches X 3 inter-arrival parameters X 6 HT X 3 demand fluctuations $=162$ classes. For each experiment class, a number of replications able to assure a 5 $\%$ confidence interval and $95 \%$ of confidence level for each performance measure have been conducted. The number of replications is often over 1,000 replications with several hours of simulation time. This is important to obtain more general results of the performance measures. The performance measures regard the following areas. The ability to deliver the job on time is measured by the total lateness. The system is evaluated by: total throughput time; average machine queues; average time in queue of the parts; average utilization of the machines. Finally, the cost estimation by the average percentage reduction of the process time of the work centers.

\section{Numerical Results}

The evaluation of the numerical results is discussed comparing the simulation results to a production system without reduction policy. The results reported concerns only the case with the couple [LT-HT] that leads to the better performance. Table 2 reports the simulation results in static demand case and without failures of the machines. The difference in terms of throughput is always under $1 \%$, therefore this performance does not change for the three policies introduced. The performance with the higher improvements is the lateness, parts in queue and time in queue of the parts. As shown in table 2, these relevant improvements are obtained with low average percentage reduction of the process time; therefore, with limited use of the resources and, therefore, costs. The centralized approach is more robust when the inter-arrival parameter change, while the distributed and proportionally decreases the improvement when the congestion level is lower. The robustness of the centralized approach is characterized by higher percentage reduction of the process time and investment costs. 
Table 2

Simulation results - Static and no failures

\begin{tabular}{|c|c|c|c|}
\hline & Distribuited & Centralized & Proportional \\
\hline & \multicolumn{3}{|c|}{ Inter-arrival EXPO (1.1) } \\
\hline Throughput & $0,973 \%$ & $0,592 \%$ & $0,296 \%$ \\
\hline Total Lateness & $-50,972 \%$ & $-49,862 \%$ & $-52,485 \%$ \\
\hline Average utilization & $-3,334 \%$ & $-7,878 \%$ & $-3,775 \%$ \\
\hline Average parts in queue & $-44,711 \%$ & $-43,322 \%$ & $-46,164 \%$ \\
\hline Average time in queue & $-46,635 \%$ & $-44,279 \%$ & $-89,706 \%$ \\
\hline \multirow[t]{3}{*}{ Average process time reduction } & $-3,643 \%$ & $-6,066 \%$ & $-3,440 \%$ \\
\hline & {$[3-18]$} & {$[3-18]$} & {$[3-18]$} \\
\hline & \multicolumn{3}{|c|}{ Inter-arrival EXPO (1.2) } \\
\hline Throughput & $0,482 \%$ & $0,448 \%$ & $-0,064 \%$ \\
\hline Total Lateness & $-28,881 \%$ & $-45,656 \%$ & $-31,049 \%$ \\
\hline Average utilization & $-1,424 \%$ & $-4,600 \%$ & $-1,684 \%$ \\
\hline Average parts in queue & $-22,435 \%$ & $-35,593 \%$ & $-24,272 \%$ \\
\hline Average time in queue & $-23,502 \%$ & $-36,086 \%$ & $-79,897 \%$ \\
\hline \multirow[t]{3}{*}{ Average process time reduction } & $-1,789 \%$ & $-3,205 \%$ & $-1,683 \%$ \\
\hline & [3-15] & [3-9] & {$[3-15]$} \\
\hline & \multicolumn{3}{|c|}{ Inter-arrival EXPO (1.3) } \\
\hline Throughput & $0,346 \%$ & $0,453 \%$ & $-0,172 \%$ \\
\hline Total Lateness & $-21,959 \%$ & $-49,360 \%$ & $-24,295 \%$ \\
\hline Average utilization & $-1,071 \%$ & $-9,346 \%$ & $-1,441 \%$ \\
\hline Average parts in queue & $-15,441 \%$ & $-36,885 \%$ & $-17,311 \%$ \\
\hline Average time in queue & $-16,124 \%$ & $-37,063 \%$ & $-69,742 \%$ \\
\hline Average process time reduction & $-1,418 \%$ & $-6,521 \%$ & $-1,344 \%$ \\
\hline
\end{tabular}

Moreover, the best interval [LT-HT] changes when the average utilization of the manufacturing system changes. For the cases of high and medium utilization the interval [LT-HT] is the same for the three policies, while in case of low utilization the policies are characterized by different best [LT-HT] interval. Table 3 reports the simulation results in static demand case and with the introduction of machines' failures. The introduction of the failures is relevant for the performance of the three policies tested. In this case, the centralized approach works worst compared to the other two policies. The proportional approach is the better and robust policy.

Table 3

Simulation results - Static and failures

\begin{tabular}{|c|c|c|c|}
\hline & Distribuited & Centralized & Proportional \\
\hline & \multicolumn{3}{|c|}{ Inter-arrival EXPO (1.1) } \\
\hline Throughput & $4,195 \%$ & $0,881 \%$ & $4,177 \%$ \\
\hline Total Lateness & $-77,934 \%$ & $-11,780 \%$ & $-78,103 \%$ \\
\hline Average utilization & $-6,314 \%$ & $-9,753 \%$ & $-6,332 \%$ \\
\hline Average parts in queue & $-77,555 \%$ & $-11,594 \%$ & $-77,725 \%$ \\
\hline Average time in queue & $-80,191 \%$ & $-11,763 \%$ & $-80,353 \%$ \\
\hline \multirow[t]{3}{*}{ Average process time reduction } & $-8,994 \%$ & $-9,775 \%$ & $-8,921 \%$ \\
\hline & \multicolumn{3}{|c|}{ Inter-arrival EXPO (1.2) } \\
\hline & [3-12] & [3-12] & [3-12] \\
\hline Throughput & $1,176 \%$ & $0,642 \%$ & $1,572 \%$ \\
\hline Total Lateness & $-51,068 \%$ & $-32,487 \%$ & $-89,196 \%$ \\
\hline Average utilization & $-7,093 \%$ & $-9,940 \%$ & $-3,327 \%$ \\
\hline Average parts in queue & $-48,359 \%$ & $-30,243 \%$ & $-84,808 \%$ \\
\hline Average time in queue & $-53,200 \%$ & $-32,458 \%$ & $-85,430 \%$ \\
\hline \multirow[t]{3}{*}{ Average process time reduction } & $-7,252 \%$ & $-8,670 \%$ & $-3,398 \%$ \\
\hline & \multicolumn{3}{|c|}{ Inter-arrival EXPO (1.3) } \\
\hline & [3-9] & [3-9] & {$[3-9]$} \\
\hline Throughput & $0,766 \%$ & $0,796 \%$ & $1,150 \%$ \\
\hline Total Lateness & $-36,029 \%$ & $-26,207 \%$ & $-87,753 \%$ \\
\hline Average utilization & $-5,911 \%$ & $-10,645 \%$ & $-3,834 \%$ \\
\hline Average parts in queue & $-32,822 \%$ & $-23,174 \%$ & $-81,307 \%$ \\
\hline Average time in queue & $-37,850 \%$ & $-25,573 \%$ & $-81,130 \%$ \\
\hline Average process time reduction & $-5,911 \%$ & $-9,421 \%$ & $-3,434 \%$ \\
\hline
\end{tabular}


Fig. 4 shows the comparison of lateness performance among the policies tested $(\mathrm{C}$ centralized, D distributed and $\mathrm{P}$ proportional) with and without failures ( $\mathrm{F}$ denotes the results with the introduction of failures). The results highlight how the proportional approach leads to better results when the failures are introduced.

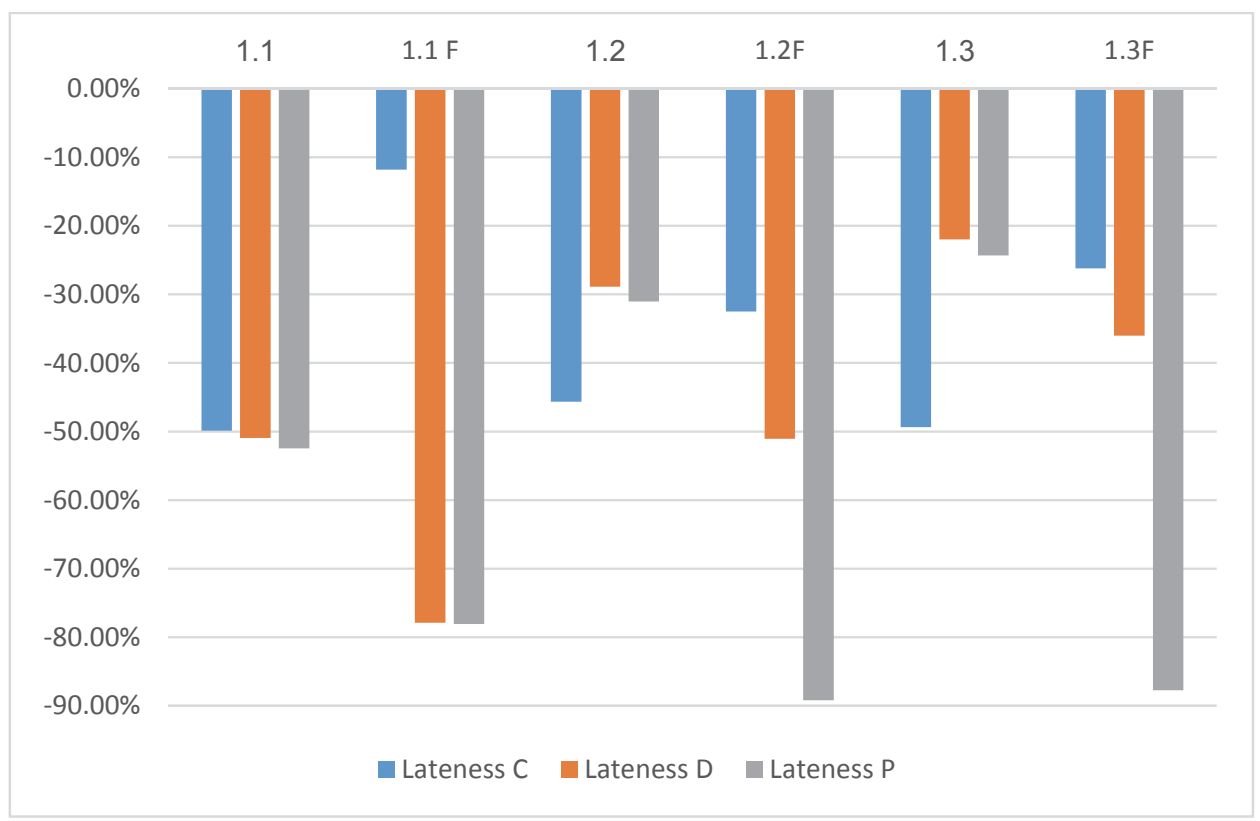

Fig. 4. Results comparison with failures

Table 4 reports the simulation results in dynamic demand case, with failures of the machines and demand fluctuations. The throughput performance does not change using the policies proposed.

The proportional policy leads to the better performance in terms of lateness, average time in queue and parts in queue. This results are supported by an average reduction of the process time about $6 \%$. When the demand fluctuations are more rapid (lower period time of changes) the improvements of the performance reduces for all policies. Moreover, the rapidity of demand changes does not influence the values $[L T-H T]$ that leads to the better performance measures. The centralized policy works better with higher value of HT than the distributed and proportional policies.

Table 4

Simulation results - Static, failures and demand fluctuations

\begin{tabular}{|c|c|c|c|c|c|c|c|c|c|}
\hline & \multicolumn{3}{|c|}{ Distributed } & \multicolumn{3}{|c|}{ Proportional } & \multicolumn{3}{|c|}{ Centralized } \\
\hline & \multicolumn{3}{|c|}{ [3-9] } & \multicolumn{3}{|c|}{ [3-9] } & \multicolumn{3}{|c|}{ [3-18] } \\
\hline & 350 & 500 & 650 & 350 & 500 & 650 & 350 & 500 & 650 \\
\hline Throughput & $0,41 \%$ & $0,05 \%$ & $0,36 \%$ & $0,18 \%$ & $0,40 \%$ & $0,40 \%$ & $0,36 \%$ & $-0,05 \%$ & $0,24 \%$ \\
\hline Total Lateness & $-45,46 \%$ & $-49,30 \%$ & $-51,06 \%$ & $-51,64 \%$ & $-53,78 \%$ & $-57,54 \%$ & $-43,37 \%$ & $-46,63 \%$ & $-46,72 \%$ \\
\hline Average utilization & $-4,43 \%$ & $-4,57 \%$ & $-4,56 \%$ & $-6,15 \%$ & $-6,55 \%$ & $-6,60 \%$ & $-7,91 \%$ & $-8,56 \%$ & $-8,26 \%$ \\
\hline $\begin{array}{c}\text { Average parts in } \\
\text { queue }\end{array}$ & $-35,85 \%$ & $-39,72 \%$ & $-41,14 \%$ & $-40,97 \%$ & $-43,52 \%$ & $-46,84 \%$ & $-34,18 \%$ & $-37,75 \%$ & $-37,82 \%$ \\
\hline $\begin{array}{c}\text { Average time in } \\
\text { queue }\end{array}$ & $-37,88 \%$ & $-41,59 \%$ & $-42,88 \%$ & $-43,26 \%$ & $-45,82 \%$ & $-48,73 \%$ & $-34,85 \%$ & $-38,18 \%$ & $-38,24 \%$ \\
\hline $\begin{array}{l}\text { Average process } \\
\text { time reduction }\end{array}$ & $-4,47 \%$ & $-4,55 \%$ & $-4,45 \%$ & $-5,95 \%$ & $-6,01 \%$ & $-5,90 \%$ & $-5,78 \%$ & $-5,76 \%$ & $-5,72 \%$ \\
\hline
\end{tabular}




\section{Conclusions and future developments}

The research presented three approaches to allocate improvements in manufacturing systems controlling the process time: centralized, distributed and proportional. The approaches are based on the workload control methodology of the manufacturing system deciding which work center and how many resources use to reduce the process time. A simulation environment has been developed to test the proposed policies in static/dynamic demand and including the machine breakdowns. The simulation results are compared to a system without process time control. The main performance measures with relevant improvements are the lateness, average queue and time in queue of the parts (throughput time of the parts).

The centralized policy is the better policy in case of static demand and no relevant problem of machine failures for different average utilization of the manufacturing system. The introduction of relevant machine breakdowns highlights how the proportional policy is the better. The proportional policy is the better also in case of demand fluctuations. The rapidity of demand changes reduces the improvements of the process time control policies.

The average percentage of the process time reduction highlights that the proposed policies can be supported with limited costs.

The results of this research are more complete because the simulation model developed is more detailed and general than the model proposed in literature as queue networks, system dynamics, etc. The implications for industrial environment, the results can help managers deciding how to allocate the limited resources and investment programs. Moreover, the simulation model can support the decisions when the manufacturing states change.

Future development paths concerns the inclusion of workload control acceptance of the orders in the manufacturing system; the computation of the workload corrected considering the sequence of the operations to perform; the computation of dynamic threshold levels adapted by the manufacturing system conditions.

\section{Acknowledgment}

The authors would like to thank the annonymous referees for constructive comments on earlier version of this paper.

\section{References}

Battini, D., Faccio, M., Persona, A., \& Sgarbossa, F. (2009). Evaluation of the mixed-model assembly line balancing problem with variable operation times and product mix. International Journal of Services and Operations Management, 6(2), 126-148.

Bhuiyan, N., \& Baghel, A. (2005). An overview of continuous improvement: from the past to the present. Management Decision, 43(5), 761-771.

Fernandes, N. O., \& Carmo-Silva, S. (2011). Workload control under continuous order release. International Journal of Production Economics, 131(1), 257-262.

Fernandes, N. O., Land, M. J., \& Carmo-Silva, S. (2014). Workload control in unbalanced job shops. International Journal of Production Research, 52(3), 679-690.

Filho, M. G., \& Uzsoy, R. (2013). The impact of simultaneous continuous improvement in setup time and repair time on manufacturing cycle times under uncertain conditions. International Journal of Production Research, 51(2), 447-464.

Godinho Filho, M., \& Uzsoy, R. (2011). The effect of shop floor continuous improvement programs on the lot size-cycle time relationship in a multi-product single-machine environment. The International Journal of Advanced Manufacturing Technology, 52(5-8), 669-681. 
Godinho Filho, M., \& Utiyama, M. H. R. (2015). Comparing different strategies for the allocation of improvement programmes in a flow shop environment. The International Journal of Advanced Manufacturing Technology, 77(5-8), 1365-1385.

Godinho Filho, M., \& Uzsoy, R. (2014). Assessing the impact of alternative continuous improvement programmes in a flow shop using system dynamics. International Journal of Production Research, 52(10), 3014-3031.

Goldratt, E., \& Cox, J. (1984). The goal: excellence in manufacturing. North River Press, Croton-onHudson.

Goldratt, E., \& Fox, R. E. (1986). The Race. Great Barrington, MA: North River Press.

Godinho Filho, M., de Andrade Guimarães, A., \& Oprime, P. C. (2013). Guiding improvement programs towards lead time reduction in a single-machine environment. The International Journal of Advanced Manufacturing Technology, 66(9-12), 1987-1998.

Janiak, A. (1989). Minimization of the blooming mill standstills-mathematical model, suboptimal algorithms. Mechanika, 8(2), 37-49.

Janiak, A., Krysiak, T., \& Trela, R. (2011). Scheduling problems with learning and ageing effects: a survey. Decision Making in Manufacturing and Services, 5(1-2), 19-36.

Luo, X., Li, W., Tu, Y., Xue, D., \& Tang, J. (2010). Optimal resource allocation for hybrid flow shop in one-of-a-kind production. International Journal of Computer Integrated Manufacturing, 23(2), 146154.

Mokhtari, H., Abadi, I. N. K., \& Cheraghalikhani, A. (2011). A multi-objective flow shop scheduling with resource-dependent processing times: trade-off between makespan and cost of resources. International Journal of Production Research, 49(19), 5851-5875.

Moon, I., Lee, S., Shin, M., \& Ryu, K. (2016). Evolutionary resource assignment for workload-based production scheduling. Journal of Intelligent Manufacturing, 27(2), 375-388.

Niu, G., Sun, S., Lafon, P., Zhang, Y., \& Wang, J. (2012). Two decompositions for the bicriteria jobshop scheduling problem with discretely controllable processing times. International Journal of Production Research, 50(24), 7415-7427.

Pande, P., Neuman, R. P., \& Cavanagh, R. R. (2000). The Six Sigma Way: How GE, Motorola and Other Top companies are Honing their Performance. New York: McGraw-Hill.

Renna, P. (2010). Capacity reconfiguration management in reconfigurable manufacturing systems. International Journal of Advanced Manufacturing Technology, 46(1-4), 395-404.

Renna, P. (2013a). Virtual job shop approach based on reconfigurable machines. International Journal of Services and Operations Management, 14(4), 445-465.

Renna, P. (2013b). Controllable processing time policies for job shop manufacturing system. The International Journal of Advanced Manufacturing Technology, 67(9-12), 2127-2136.

Renna, P. (2015a). Deteriorating job scheduling problem in a job-shop manufacturing system by multiagent system. International Journal of Computer Integrated Manufacturing, 28(9), 936-945.

Renna, P. (2015b). Workload Control Policies under continuous order release. Production Engineering, 9(5), 655-664.

Selim, A.M., \& Taylan, I.T. (2011). Single CNC machine scheduling with controllable processing times to minimize total weighted tardiness. Computers and Operational Research, 17(10), 533-541.

Shabtay, D., \& Steiner, G. (2007). A survey of scheduling with controllable processing times. Discrete Applied Mathematics, 155(13), 1643-1666.

Stevenson*, M., Hendry, L. C., \& Kingsman†, B. G. (2005). A review of production planning and control: the applicability of key concepts to the make-to-order industry. International journal of production research, 43(5), 869-898.

Thürer, M., Stevenson, M., \& Land, M. J. (2016). On the integration of input and output control: Workload Control order release. International Journal of Production Economics, 174, 43-53.

Thürer, M., Stevenson, M., Silva, C., Land, M. J., \& Fredendall, L. D. (2012). Workload Control and Order Release: A Lean Solution for Make-to-Order Companies. Production and Operations Management, 21(5), 939-953. 
Thürer, M., Land, M. J., Stevenson, M., Fredendall, L. D., \& Godinho Filho, M. (2015). Concerning Workload Control and Order Release: The Pre-Shop Pool Sequencing Decision. Production and Operations Management, 24(7), 1179-1192.

Uruk, Z., Gultekin, H., \& Akturk, M. S. (2013). Two-machine flowshop scheduling with flexible operations and controllable processing times. Computers \& Operations Research, 40(2), 639-653.

Womack, J.P., Jones, D.T., \& Ross, D. (1990). The machine that changed the world. Harper Perennial, New York.

Yildiz, S., Akturk, M. S., \& Karasan, O. E. (2011). Bicriteria robotic cell scheduling with controllable processing times. International Journal of Production Research, 49(2), 569-583.

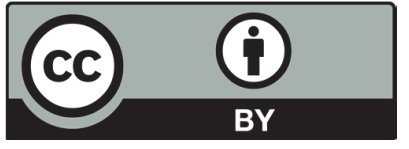

(C) 2016 by the authors; licensee Growing Science, Canada. This is an open access article distributed under the terms and conditions of the Creative Commons Attribution (CCBY) license (http://creativecommons.org/licenses/by/4.0/). 